\title{
New observational method framework for embedded walls
}

Stuart Hardy MEng, PhD, DIC, MICE, CENG Associate Director, Ove Arup \& Partners, London, UK

Duncan Nicholson BSC, MSC, DIC, CEng, MICE Fellow, Ove Arup \& Partners, London, UK

(corresponding author: duncan.nicholson@arup.com)

Peter Ingram BEng, PhD, MICE, CEng

Associate, Ove Arup \& Partners, London, UK

\author{
Asim Gaba MA, MSc, DIC, LLB, CEng, FICE, FGS, MHKIE, MASCE, \\ MCIArb \\ Director and Trustee, Ove Arup \& Partners, London, UK \\ Ying Chen BEng, BSC, MSc, MICE \\ PhD student, Engineering Department, University of Cambridge, \\ Cambridge, UK (Orcid:0000-0001-6027-1791) \\ Giovanna Biscontin PhD \\ Lecturer, Engineering Department, University of Cambridge, Cambridge, UK
}

This paper introduces the new holistic observational method (OM) framework described in the Construction Industry Research and Information Association's guide C760 - the new revision to the Embedded Retaining Walls design guide C580. This new OM framework is described by four approaches, and these are explained with reference to case histories. The maximum benefit is achieved by back-analysing case histories in similar ground conditions to derive the most probable soil parameters. These parameters can then be used in an ab initio design to maximise saving in the wall thickness, toe embedment and propping requirements. A contingency plan is based on characteristic soil parameters, and this may involve additional propping. The term 'ipso tempore' is introduced for the circumstance where wall redesign occurs after construction starts. This may be to achieve saving in propping where movements are much smaller than predicted. Alternatively, additional propping or ground treatment may be required, and this is consistent with Peck's 'best-way-out' approach.

\section{Introduction}

The observational method $(\mathrm{OM})$ in geotechnical engineering was formulated for the first time by Peck (1969) in his Rankine Lecture. Since the original work by Peck, the method has been revisited on many occasions (e.g. Gaba et al., 2003; Nicholson et al., 1999; Powderham, 1994). Despite its obvious benefits to the construction industry, the OM has not reached its full potential for retaining wall applications. The reason for the reticence to adopt the OM may be due to the absence of a code of practice for its implementation, a misconception of perceived increased risk, insufficient time available in the design programme or perhaps the increased fragmentation of the construction industry.

The Eurocode for geotechnical design (BS EN 1997-1; BSI, 2004), Eurocode 7 (EC7), is the first design code that specifically permits the design of geotechnical structures to be undertaken using the OM, although it gives very little guidance or requirements. As part of the update to the Construction Industry Research and Information Association's (Ciria) guide C580 for the design of embedded retaining walls (C760 (Gaba et al., 2017)), a new classification system and approach to the implementation of the $\mathrm{OM}$ was introduced. The intention was to bring together the previous work undertaken on the $\mathrm{OM}$ in a logical and structured way to allow for its more widespread implementation, which has been presented by Hardy et al. (2017). This new classification and implementation approach is described here with examples of its application drawn from a number of case histories, including the Crossrail project recently completed in central London.

\section{Background}

Peck (1969)

In his Rankine Lecture, Peck (1969) introduced two approaches to the implementation of the OM: ab initio, where the intention is to use the OM from the start of the project, and the 'best way out', where construction is not going as planned and some intervention is required to prevent an ultimate limit state (ULS) or serviceability limit state (SLS) from occurring.

\section{Ab initio}

In Peck's (1969) original description of $a b$ initio, the design of a particular geotechnical structure would be undertaken using the most probable parameters for the soil and structural behaviour. Separately, a set of contingency measures would be developed that would assure stability of the wall if the behaviour tended towards characteristic design (or the equivalent definition of moderately conservative). Depending on the observed response, the construction would either continue following the most probable behaviour or the pre-planned contingency measures would be implemented. For an embedded retaining wall, the wall embedment and structural design would be completed according to the most probable design with plans for an alternative construction sequence, likely to involve more levels of props, or an alternative excavation sequence. In the case of embedded retaining walls, it is an obvious but important consideration that once the wall is installed, its embedment length and structural design cannot be changed easily, and therefore only the 
construction sequence and propping structures, including ground treatment, can be modified.

\section{Best way out}

In contrast to $a b$ initio, the best way out is not planned from the start of the project but is implemented during the construction stage when unacceptable, or unexpected, movements occur. Rather than offering savings in programme and materials, the best way out is used to prevent failure or unacceptable movements. For the case of an embedded retaining wall, the process requires the rigorous back-analysis of the wall performance to date and recalibration of the parameters used to predict the soil and structural behaviour. Using the recalibrated parameters, the remedial measures required to ensure long-term stability of the structure can be designed and implemented.

\section{Ciria C185 (Nicholson et al., 1999)}

Nicholson et al. (1999) provided guidance on the application of the OM to any type of geotechnical structure by building on the initial work of Peck (1969). In describing the ab initio approach to the OM, Ciria C185 makes a significant departure from the original description by Peck. Instead of starting with a most probable design and having a characteristic design as a contingency, $\mathrm{C} 185$ proposes starting with a characteristic design and having a most probable design as a possible modification (i.e. an improvement). It is important to note that the potential savings from this approach are reduced, as the wall embedment and structural design cannot be modified.

In addition, $\mathrm{C} 185$ provides a broad $\mathrm{OM}$ definition as a continuous, managed, integrated process of design, construction control, monitoring and review. This enables previously defined modifications to be incorporated during or after construction as appropriate. Linking the design and construction process is important to control safety and maximise economy.

\section{New OM framework}

\section{Review of current approaches}

The approaches to $a b$ initio proposed by Peck (1969) and Nicholson et al. (1999) are equally valid but address the balance between risk and opportunity quite differently. Peck's original definition saw the application of contingency measures as a risk mitigation, whereas Nicholson et al. saw the application of modification as an opportunity. By being more cautious in their approach, the method of ab initio proposed by Nicholson et al. could not maximise the possible savings in cost and programme. If the embedded retaining wall is constructed in accordance with a structural and geotechnical design assuming characteristic parameters, the embedment depth, structural thickness and reinforcement requirements will be more onerous than if the most probable parameters had been assumed and, once constructed, evidently cannot be changed. Economies can therefore be made only by modifications to the excavation sequence and support to the wall. These savings may be significant, but can never match the savings possible if the most probable behaviour had been assumed for the design from the start.

The confusion generated by the different base design assumptions described under the same name, but leading to different design and performance outcomes, may partially explain why the $\mathrm{OM}$ has not gained significant traction in the construction industry since its introduction in Peck's Rankine Lecture.

\section{Ciria C760"s (Gaba et al., 2017) holistic approach to OM}

To overcome the apparent inconsistencies in the approach to the application of the OM, Gaba et al. (2017), the authors of the new Ciria guidance on the design of embedded retaining walls, C760, took the opportunity to introduce a new framework that aims to unify and incorporate all previous definitions. It was hoped that a new consistent framework to the application of the OM to embedded retaining walls would encourage its application during the construction stage. The new framework is particularly relevant to large infrastructure projects, but can also be used for other types of geotechnical structures.

Under the new framework, the $\mathrm{OM}$ is divided into two broad categories: $a b$ initio in which the application of the $\mathrm{OM}$ is planned prior to wall installation; and a new term is introduced, 'ipso tempore', where the $\mathrm{OM}$ is initiated after wall installation has started. The two broad categories are divided into two further sub-categories as described in the following sections.

\section{Approach A: ab initio optimistically proactive}

Approach A is akin to $a b$ initio as defined by Peck (1969) in his Rankine Lecture. The geotechnical and structural design of the wall is undertaken assuming the most probable behaviour, and therefore savings in materials are maximised. On the assumption of the most probable behaviour, a fully developed construction sequence is developed. In parallel, an alternative construction sequence is devised that assumes a characteristic behaviour of the ground and the wall. With the geotechnical and structural capacity of the wall defined by the assumption of the most probable behaviour, it is inevitable that an alternative construction sequence will require additional support to the wall to ensure stability and that the structural forces are within the wall and prop capacity. On the basis of serviceability predictions, trigger limits are set to control the behaviour of the wall relative to the characteristic and most probable predictions. Once excavation of the wall has started, the observations are compared to the characteristic and most probable predictions, and a decision is made on which of the defined construction sequences is to be followed.

Peck (1969) described a successful application of approach A for the prop design at the Harris Bank excavation in Chicago. Based on the back-analysis of previous basement case histories, Peck defined the prop force envelopes for conservative and mean conditions. The mean design was used for the 39 props at the Harris Bank excavation. During construction, three additional props were installed as the contingency plan. Peck's prop force envelope approach was extended in Ciria C517 
(Twine and Roscoe, 1999) and in the Recommendations on Excavations: EAB (German Geotechnical Society, 1967). Comparisons of these approaches with numerical analysis for stiff clays have been carried out by Katsigiannis et al. (2015). The $E A B$ was found to provide better agreement with the numerical analysis for deep excavations with more than four prop levels.

\section{Approach B: ab initio cautiously proactive}

Approach B is akin to ab initio as defined by Nicholson et al. (1999) in Ciria C185. The geotechnical and structural design of the wall is undertaken with characteristic assumptions for the ground and the wall behaviour. At this stage, the design is compliant with the requirements of 'design by calculation' as defined in EC7, and monitoring would not be necessary to validate the assumptions. In parallel to the characteristic design, a construction sequence is developed with the most probable behaviour assumed for the ground and the wall. Due to the enhanced parameters, it is likely that for this set of assumptions, prop levels could be omitted while maintaining the wall stability and structural capacity. It is clear that the material used in the wall construction cannot be optimised at this point, but savings can be made in the construction sequence and the amount of support provided. Trigger limits are then set based on SLS analyses adopting characteristic and most probable behaviours and excavation of the wall started. Depending on how observations compare to the characteristic and most probable predictions, it can be decided if the modifications based on the most probable analysis can be implemented or not.

The Batheaston Bypass project (Nicholson et al., 1998) is an example of approach B. The initial design was based on characteristic drained soil parameters, and a temporary row of props at ground level was required. Immediately post tender, the contractor developed a temporary works excavation design using most probable undrained strength parameters based on the backanalysis of a similar cantilever excavation in the same geological conditions. A contingency plan was also created in case the wall behaviour had been more akin to that calculated with the characteristic drained soil parameters. This plan involved excavating the berm in bays to install the permanent formation-level props. Following a detailed review, it was agreed to modify the design by omitting the ground-level temporary props. During construction, the monitoring system trigger values were not exceeded and it was not necessary to implement the contingency plan.

\section{Choice between approaches $A$ and $B$ for $a b$ initio}

The choice between approaches A and B when applying the OM to embedded retaining walls will depend primarily on the familiarity of the project team, and particularly the designer, with the prevailing ground conditions at the site under consideration. If the ground conditions are well known and there is an adequate number of case histories for similar structures in the same ground conditions, back-analysis of these can be undertaken to compare with the most probable parameters derived from site investigation data. The designer may then be confident in using approach A, provided that the contractor and client are involved in the process and are actively engaged in its implementation. It would be foolhardy to use approach A when working in unfamiliar ground conditions (where approach B may be more suitable) or when working with a project team that does not understand or is not fully engaged with the OM process (in which case OM should not be used at all). Figure 1 shows the process the project team can take to choose between approaches A and B.

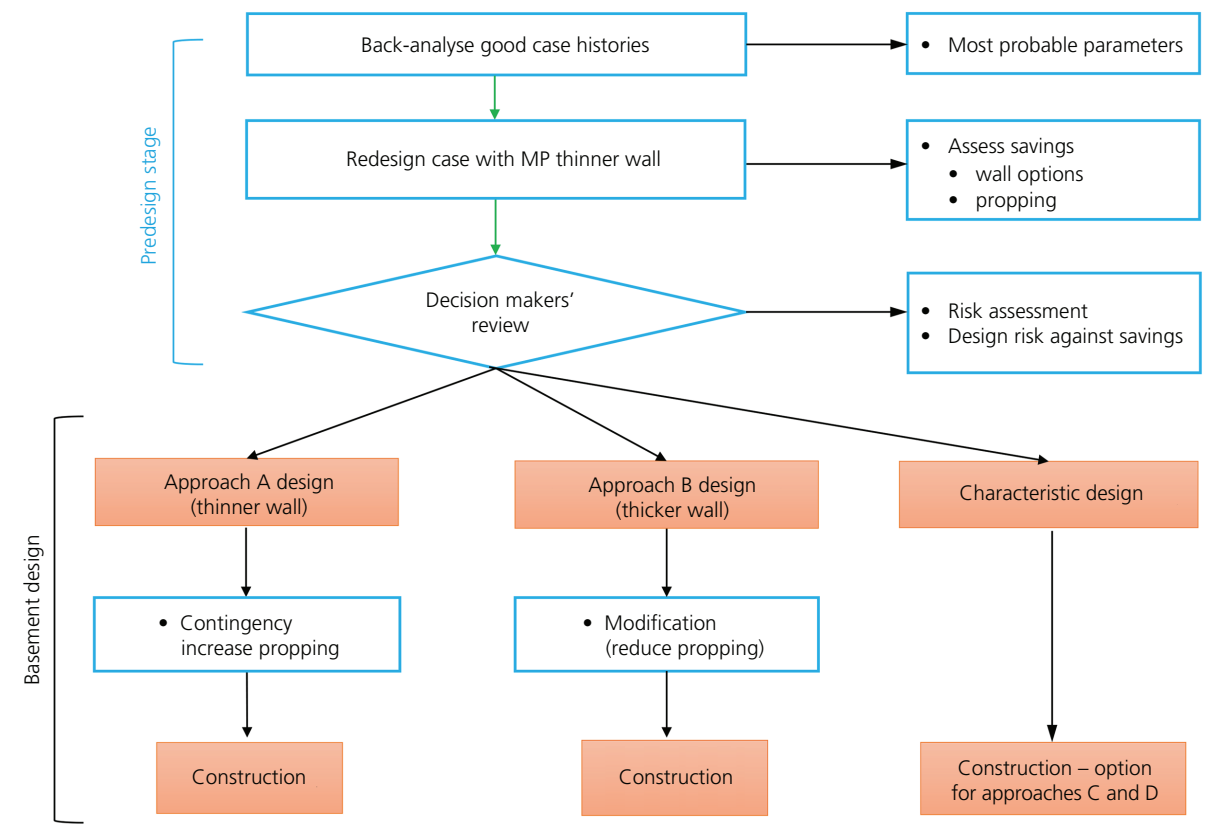

Figure 1. Flow chart for selecting approach A or B 


\section{Approach C: ipso tempore proactive to make modifications}

Ciria C760 (Gaba et al., 2017) defines ipso tempore approach C as the $\mathrm{OM}$ being implemented during the construction stage of a project, to make improvements proactively to the construction sequence that have not previously been formally defined. When following approach $\mathrm{C}$, the design of the wall has been completed in accordance with the requirements of the design-by-calculation approach defined in EC7 and is therefore akin to the characteristic design defined in approach $\mathrm{B}$. The significant difference is that when excavation started, there was no intention to implement the OM, and therefore no alternative construction sequence was prepared from the outset of the project. At some stage during the construction sequence, the design team realises that the wall is performing better than predicted and proactively decides to change to the future construction sequence. At this stage, it is important that the original designer of the initial construction stages of the wall undertakes a thorough audit of the wall's behaviour and the construction sequence that has been followed to allow a rigorous back-analysis of the wall to be performed. The audit must include as a minimum the observed wall and ground movements, prop loads, excavation sequence and levels and surcharges applied to the wall. Once the audit is complete, a rigorous back-analysis of the wall can be completed to recalibrate the assumed parameters. These recalibrated parameters can be used to forward-predict the behaviour of the wall to completion and to design an improved construction sequence. Associated SLS analyses will be required at this stage using the recalibrated parameters in order to set trigger limits that ensure that the performance of the wall in the subsequent construction stages is in line with the recalibrated predictions. The benefits in adopting approach $\mathrm{C}$ are similar to those defined in ab initio approach $\mathrm{B}$.

Despite not previously being formally defined, approach $\mathrm{C}$ has been the most commonly adopted. The Crossrail case history at Tottenham Court Road western ticket hall (Chen et al., 2015; Yeow et al., 2014) is a recent example.

\section{Approach D: ipso tempore reactive to make corrections} Ipso tempore approach $\mathrm{D}$ is akin to the best way out defined by Peck (1969). In common with approach C, there was no intention to apply the OM from the start of the project; however, movements are larger than predicted and the project team decides to implement the OM to ensure that an SLS or ULS failure does not occur. These movements are often associated with wall installation or ground treatment operations. This is in contrast to approach $\mathrm{C}$ when the introduction of the $\mathrm{OM}$ is implemented because movements are smaller than expected.

Once the decision is made to implement the $\mathrm{OM}$, the process is similar to that described for approach $\mathrm{C}$. The first stage is to undertake an audit of the observations and the construction process to that point and to recalibrate the analytical model to make a forward prediction to the completion of construction. To prevent an SLS or ULS from developing, it is likely that additional support to the wall or a revised construction sequence will be needed. An example of approach D is at Newton station in Singapore (Nicholson, 1987) where an unforeseen buried channel infilled with marine clay was encountered during diaphragm wall installation. A jet grout raft was then used to provide additional propping to the wall below the formation level (Gaba, 1990).

\section{Summary of approaches to the OM}

A thorough discussion on the different approaches to the OM can be found in Ciria C760 (Gaba et al., 2017). The paper by Chen et al. (2015) and Table 7.2 in C760 give a summary of the key points related to each approach. A simplified summary of approaches A-D is provided in Table 1.

\section{Interpretation of site investigation data}

\section{Definition of parameters}

One of the principal requirements of EC7 when applying the OM is that 'the range of possible behaviour shall be assessed and it shall be shown that there is an acceptable probability that the actual behaviour will be within the acceptable limits' (BSI, 2004: p. 36).

In this current framework, the range of possible behaviour is reduced to 'characteristic' and 'most probable'. The term 'characteristic' was introduced with BS EN 1997-1, but for most purposes can be taken as being equivalent to 'representative' used in BS 8002:1994

Table 1. Summary of OM approaches

\begin{tabular}{|c|c|c|c|c|}
\hline & \multicolumn{2}{|c|}{$A b$ initio (from the start) } & \multicolumn{2}{|c|}{ Ipso tempore (in the moment) } \\
\hline & $\begin{array}{c}\text { A } \\
\text { Optimistic (Peck, 1969) }\end{array}$ & $\begin{array}{c}\text { B } \\
\text { Cautious } \\
\text { (Ciria C185) }\end{array}$ & $\begin{array}{c}\text { C } \\
\text { Proactive modifications } \\
(\text { Ciria C760) }\end{array}$ & $\begin{array}{c}\text { D } \\
\text { Reactive contingencies } \\
\text { (Peck, 1969) }\end{array}$ \\
\hline $\begin{array}{l}\text { OM design } \\
\text { work starts }\end{array}$ & \multicolumn{2}{|c|}{ Before wall construction } & \multicolumn{2}{|c|}{ After wall construction } \\
\hline $\begin{array}{l}\text { Starting OM } \\
\text { design }\end{array}$ & Most probable parameters & $\begin{array}{c}\text { Characteristic } \\
\text { parameters }\end{array}$ & \multicolumn{2}{|c|}{ From back-analysis of initial stages } \\
\hline $\begin{array}{l}\text { Existing } \\
\text { back-analysis }\end{array}$ & Necessary & Preferred & \multicolumn{2}{|c|}{ Use initial construction stages } \\
\hline Design objectives & $\begin{array}{l}\text { Optimise wall } \\
\text { thickness/depth/propping }\end{array}$ & $\begin{array}{l}\text { Optimise wall } \\
\text { propping }\end{array}$ & Reduce wall support & Increase wall support \\
\hline Design plans & Use contingency plan & Use modification plan & Introduce modification plan & Introduce contingency plan \\
\hline
\end{tabular}


(BSI, 1994) and 'moderately conservative' used in Ciria C580 (Gaba et al., 2003). Other definitions, such as 'worst credible' or 'more probable with progressive modification' (Powderham, 1994) could be applied within the framework; however, for simplicity only 'characteristic' and 'most probable' are discussed here.

It is important to bear in mind that when choosing characteristic or most probable parameters for the design of an embedded retaining wall, it is not only the selection of soil strength and stiffness that are important. There are many facets of wall behaviour that should also be considered, including wall stiffness, surcharges, groundwater level, prop stiffness, undrained against drained behaviour, in situ stresses, wall installation effects, numerical model and design assumptions.

\section{Characteristic parameters}

Clause 2.4.5.2 (2) of EC7 states that 'the characteristic value of a geotechnical parameter shall be selected as a cautious estimate of the value affecting the occurrence of the limit state' (BSI, 2004: p. 27).

The choice of characteristic value for geotechnical design has been controversial and misunderstood since the introduction of the Eurocodes. The choice of a characteristic parameter will depend on the limit state under consideration as well as the geotechnical structure being designed. For an embedded retaining wall at ULS, the volume of material mobilised at failure is large, and therefore the overall strength will be close to the average. On the other hand, an end bearing pile will be more susceptible to local variations in strength and therefore the characteristic strength should be a more cautious estimate. The use of statistics has been proposed by many researchers to provide more rigour in the choice of characteristic strength. BS EN 1990 (Eurocodes) defines the characteristic value as the $5 \%$ fractile value, although this definition is not considered appropriate for geotechnical design (Bond and Harris, 2008) and shall not be considered further here.

\section{Most probable}

Nicholson et al. (1999: p. 12) defined the most probable value of a parameter as being 'a set of parameters that represent the probabilistic mean of all possible sets of conditions. It represents, in general terms, the design condition most likely to occur in practice'.

The most probable value may be estimated initially as the arithmetical mean of the available site investigation data or may be refined by back-analysis of case history data in the same ground conditions for similar construction. The parameters that result from the back-analysis may be different from the mean of the data from the site investigation. Data from laboratory small strain stiffness, mass permeability and in situ earth pressures are often limited and may have large scatter making it difficult to assess most probable vales.

\section{Back-analysis of case histories}

The process of back-analysis described in this section of the paper could be applied to a completed project with the intention of using the parameters ab initio in approach A or B for a similar project in the same geologic conditions or during the early stages of an excavation in order to apply the OM ipso tempore using approach $\mathrm{C}$ or $\mathrm{D}$. The principles are the same whatever the approach; however, the time available to complete the exercise might be somewhat different.

It is important to adopt the back-analysis rules used for the case history and apply these to the new design.

When assessing site investigation data, it is easier to develop the 'most probable' (mean) parameters by using simple statistical methods. The characteristic parameters often include differing degrees of engineering judgement, which can make the interpretation of the back-analysis unclear.

During the back-analysis process, it is worth rerunning the case history by using the most probable parameters and assessing the reductions in wall thickness, reinforcement and prop forces compared with the original characteristic design. This will enable the costs savings to be assessed and provides information for the stakeholder review shown in Figure 1.

From an infrastructure client perspective, it is worth considering the $\mathrm{OM}$ process as a route to improving embedded wall designs in the long term. For example, the short-term use of the OM to control risk can lead into a long-term improvement in characteristic parameters and a characteristic design. An example of this approach is discussed in the paper by Gaba and McGowan (2017) for projects in Singapore.

\section{Monitoring data audit}

For approaches A and B, good-quality instrumentation and review systems can be specified which match the OM designs; see the report by Nicholson et al. (1999). Installation method and baselining have been found to be very important. With approaches $\mathrm{C}$ and $\mathrm{D}$, the existing data are harder to validate, but monitoring staff are still available on-site to interview. A review process can be introduced with the contingency/modification plans.

The best time to undertake the back-analysis is during the construction when the monitoring and construction data can be discussed with the site staff before they are demobilised. These discussions are best incorporated into the data review stage of the OM process. Section 5 of the report by Nicholson et al., (1999) discusses the management of the OM processes. Section 7 discusses the monitoring and review techniques developed for the sprayed concrete lining, and these are also relevant to excavations. Section 8 describes the design, construction monitoring and review stages for excavations.

To undertake a thorough back-analysis of a case history, a significant amount of information is required - for example, excavation details, including levels and sequence, wall 
movements from inclinometers, surveyed capping beam movements, surveyed ground and building movements, the propping layout, stiffness and installation sequence, prop forces from strain gauges, pre-stress in props from jacks and strain gauges, testing records for concrete cubes, levels and description of excavated materials and site use during the works.

One of the most critical aspects of the audit is to tie movements and forces to the corresponding excavation levels. For intermediate excavation levels, this can be difficult if the designer does not have a permanent presence on-site keeping records of excavation progress. The use of time-lapse photography can help in the process of linking together the cause and effect of excavation on wall movements. The case history data may also comprise several inclinometer records and many prop loads showing different maximum movements and forces. This leads to the dilemma of whether the inclinometer with the largest deflection or the average deflection should be back-analysed. If there is only one inclinometer, it is not possible to assess whether the measured performance is representative of an average response. Integrating inclinometer data with surface movements and prop forces can help clarify the conditions. A holistic assessment considering all available monitoring systems is critical to the success of the back-analysis.

When considering undrained behaviour, there is merit in reviewing internal piezometer data sets. However, there is often very little field evidence of the large soil suctions that are predicted by numerical modelling. Extensometers within the excavation can provide useful backup when assessing undrained conditions which are associated with no volume change.

If a published case history is being used for the back-analysis, the data available will be limited to those included in the paper if the analyst or their organisation were not involved in the project. Should critical aspects be missing, it may be advisable to abandon the back-analysis and seek other more rigorous case histories rather than use partial and potentially misleading information.

\section{Numerical modelling for the back-analysis process}

The primary variables that the numerical analyst will be attempting to match during the back-analysis process are likely to be the wall deformation and prop forces. Using the information gathered during the data audit phase, a systematic approach is required to achieve a reasonable match between the analytical model and field measurements. At each stage, significant engineering judgement is required to assess if an analytical result is acceptable or not.

A comparison of predicted and observed wall movements at each available excavation stage should be the first stage of the calibration process. If the deformed shape of the wall is similar but the magnitude of the displacements differs, the strength and the stiffness of the ground, and possibly the stiffness of the wall, should be the principal variables for consideration. If the deformed shape of the wall does not resemble predictions, then a more fundamental reappraisal of the wall's construction is probably needed. This should include the excavation and propping sequence and the soil behaviour (e.g. drained against undrained).

Examples of real data from the same site where some inclinometers gave deformed shapes that correlate well with predictions but with lower movements and other inclinometers showed significantly different behaviour are shown in Figure 2. To recalibrate the prediction model to match the wall movements shown in Figure 2(a), adjustment to the soil and/or structural stiffness parameters should be sufficient. The back-analysed soil stiffness may be at the upper bound of small strain triaxial test data, which can be subject to sample disturbance effects. For the example in Figure 2(b), where the deformed shape is significantly different, a reappraisal of the wall behaviour might be required. The modelling of the top and middle props or the excavation sequence up to installation may need to be reassessed.

The process of matching monitoring data with a recalibrated analysis is inevitably iterative, and due to the multitude of possible variables, there will be no unique solution. It is therefore important that the variables used in the iterative process are within an acceptable range. There is merit in assessing simple elastic-plastic Mohr-Coulomb models when interpolating results. However, when extrapolating results to larger strains, then small strain models and three-dimensional effects may be important to model.

An active area of current research is the use of the Bayesian method (Cañavate-Grimal et al., 2015) for the analysis of embedded retaining walls. In this approach, each soil parameter is considered as a random variable and the output - for example, movement - is also a random variable. In this way, the relative importance of each parameter on the retaining wall behaviour can be automatically quantified and subsequently used to aid the calibration process. By reducing the numerical burden required in the Bayesian inference, the back-analysis could be run in real time during the excavation to help update deflection predictions. This method is also compatible with EC7 clause 2.4.5.2 (11): 'If statistical methods are used, the characteristic value should be derived such that the calculated probability of a worse value governing the occurrence of the limit state under consideration is not greater than 5\%' (BSI, 2004: p. 28). This enables both most probable and characteristic parameters to be reassessed.

\section{Contractual arrangements and staffing}

The contractual arrangements for a win-win situation are discussed in section 6 of the report by Nicholson et al. (1999). The value engineering clauses are useful to share risk and reward.

For fast-track projects using the $\mathrm{OM}$, an experienced designer is needed because it takes time and commitment to collect and backanalyse case histories. In complex problems, a good understanding of soil parameters and numerical models is important. 


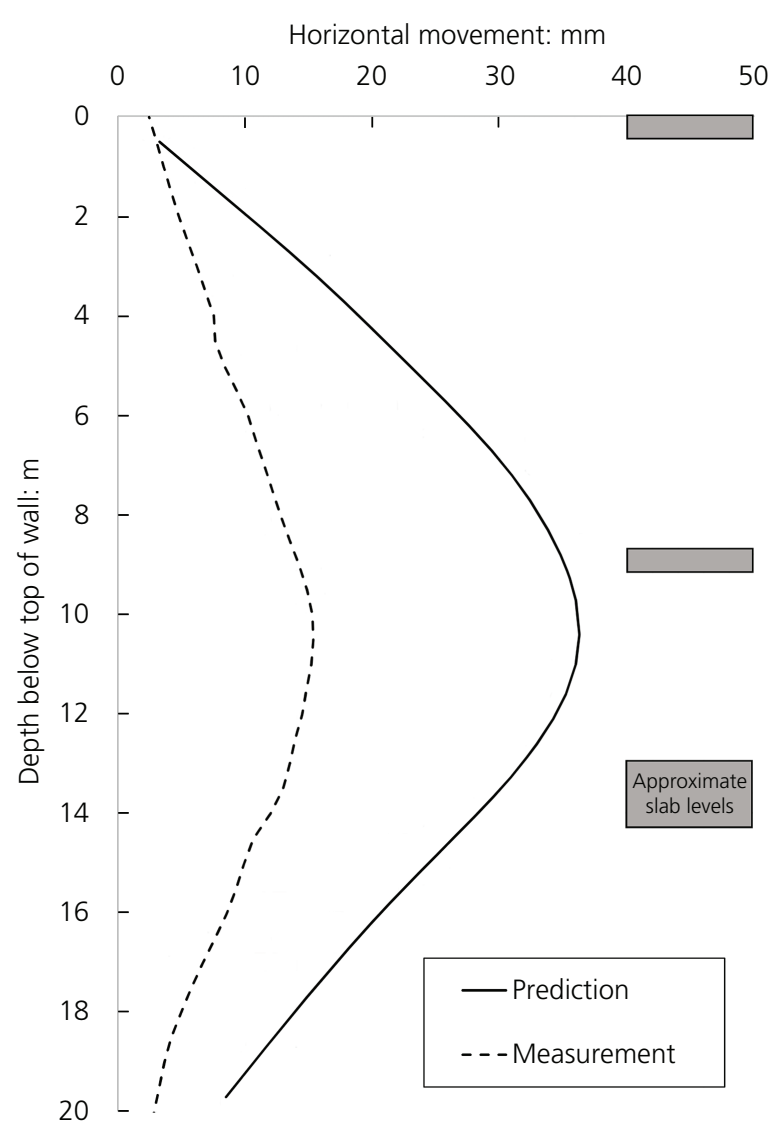

(a)

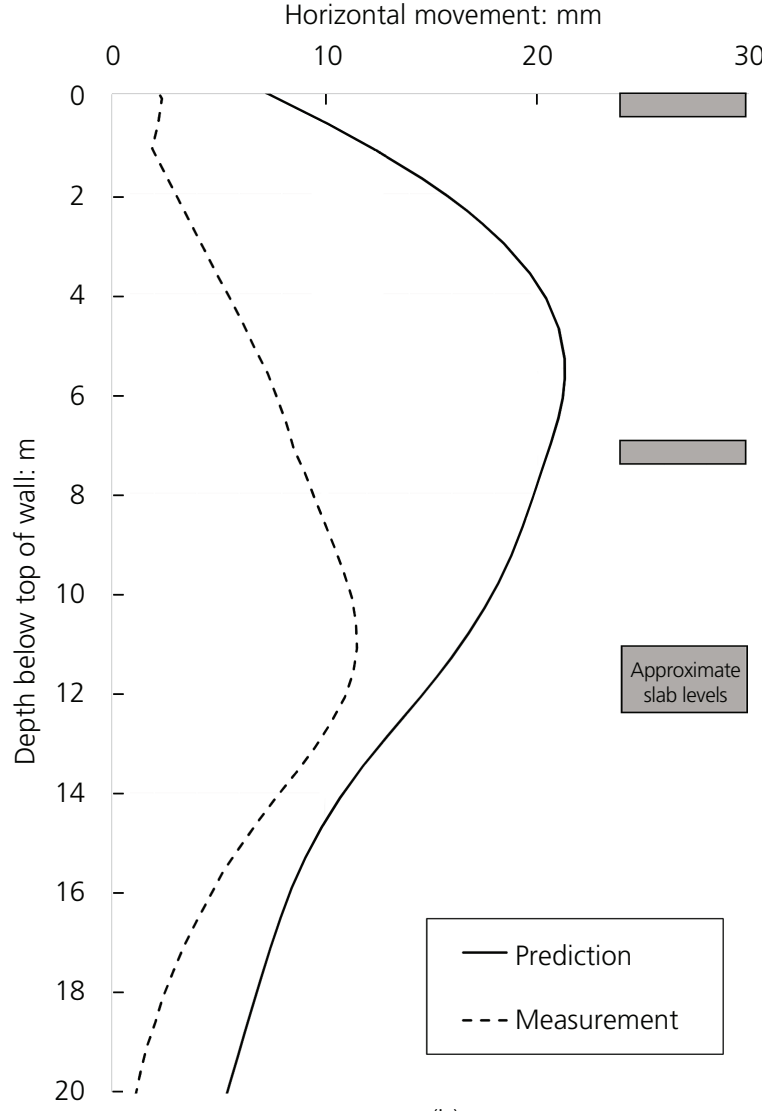

(b)

Figure 2. Example of (a) good shape but poor predicted magnitude and (b) poor deformed shape prediction

To implement the OM on-site, it is important to have engineers with construction experience because they need to develop practical contingency/modification plans and ensure that these are carried out on a busy site.

\section{Conclusions}

The OM design and construction process has been used in construction for centuries and formally defined in geotechnics for nearly 50 years. Despite the clear benefits in terms of economy, programme, partnering and clear risk allocation, there remains some reticence in the civil engineering profession to employ it widely.

The new Ciria guidance C760 proposes a new holistic framework for the OM. It identifies four approaches to implementing the OM for embedded retaining walls. It is hoped that the clarity provided by the new guidance will encourage the use of the OM, particularly using the $a b$ initio approach A. The back-analysis is an important part of the process for determining most probable soil parameters. It is important to link this to a review of soil parameters and monitoring data. It is considered that modern instrumentation systems with realtime back-analysis will help all OM approaches and provide a basis for improving characteristic designs in the long term with associated cost savings. This will be of long-term benefit to clients.

\section{Acknowledgements}

Support was provided by Ove Arup and Partners, Ltd and the UK Engineering and Physical Sciences Research Council (EPSRC) grant EP/N021614/1, the Technology Strategy Board grant 920035 for the University of Cambridge Centre for Smart Infrastructure.

\section{REFERENCES}

Bond A and Harris A (2008) Decoding Eurocode 7. Taylor \& Francis, London, UK.

BSI (1994) BS 8002:1994: Code of practice for earth retaining structures. BSI, London, UK.

BSI (2004) BS EN 1997-1:2004+A1:2013: Eurocode 7. Geotechnical design. General rules. BSI, London, UK.

Cañavate-Grimal A, Falcó A, Calderón P and Payá-Zaforteza I (2015) On the use of stochastic spectral methods in deep excavation inverse problems. Computers \& Structures 159: 41-60, https://doi.org/10. 1016/j.compstruc.2015.06.009.

Chen Y, Nicholson DP, Ingram P et al. (2015) Application of the observational method on Crossrail projects. Federation of Pilling Specialists Crossrail: a Specialist Foundation Construction Lessons Learnt Conference, London, UK, pp. 63-72.

Gaba AR (1990) Jet grouting at Newton Station. Proceedings of the 10th SE Asian Geotechnical Conference, Taipei, Taiwan, pp. 77-79.

Gaba AR and McGowan M (2017) The new Ciria C760 observational method implementation framework and its potential application to 
Geotechnical Research

Volume 5 Issue GR3
New observational method framework

for embedded walls

Hardy, Nicholson, Ingram et al. projects in Singapore. Proceedings of the GeoSS 10th Anniversary International Conference, Singapore.

Gaba AR, Simpson B, Powrie W and Beadman D (2003) Embedded Retaining Walls - Guidance for Economic Design. Construction Industry Research and Information Association (Ciria), London, UK, Report C580. Gaba AR, Hardy S, Doughty L, Selemetas D and Powrie W (2017) Embedded Retaining Walls - Guidance for Design. Ciria, London, UK, Report C760.

German Geotechnical Society (1967) Recommendation on Excavations: $E A B, 3$ rd edn. Ernst \& Sohn, Rotterdam, the Netherlands, pp. 482-488.

Hardy S, Nicholson DP, Ingram P et al. (2017) New observational method framework and application. Proceedings of the 19th International Conference on Soil Mechanics and Geotechnical Engineering, Seoul, South Korea, pp. 1995-1998.

Katsigiannis G, Schweiger HF, Ferreira P and Fuentes R (2015) Design of deep supported excavations: comparison between numerical and empirical methods. Proceedings of the 5th Conference on Geotechnical Safety and Risk, Rotterdam, the Netherlands, pp. 482-488.

Nicholson DP (1987) The design and performance of retaining walls at Newton Station. Proceedings of the Singapore Mass Rapid Transit Conference, 6-9 April, Singapore, pp. 147-154.
Nicholson DP, Cunningham G, Armstrong A and Boothman J (1998) Value achieved using the observational method on the retained cutting at the Batheaston/Swainwick bypass. Proceedings of the Seminar on the Value of Geotechnics in Construction, London, UK, pp. 123-146.

Nicholson DP, Tse C and Penny C (1999) The Observational Method in Ground Engineering - Principles and Applications. Ciria, London, UK, Report 185.

Peck RB (1969) Advantages and limitations of the observational method in applied soil mechanics, Ninth Rankine Lecture. Géotechnique 19(2): 171-187, https://doi.org/10.1680/geot.1969.19.2.171.

Powderham AJ (1994) An overview of the observational method: development in cut and cover and bored tunnelling projects. Géotechnique 44(4): 619-636, https://doi.org/10.1680/geot.1994. 44.4.619.

Twine D and Roscoe H (1999) Temporary Propping of Deep Excavations - Guidance on Design. Ciria, London, UK, Report C517.

Yeow HC, Nicholson DP, Man CL et al. (2014) Application of observational method at Crossrail Tottenham Court Road station, UK. Proceedings of the Institution of Civil Engineers - Geotechnical Engineering 167(2): 182-193, https://doi.org/10.1680/geng.13.00035.

\section{How can you contribute?}

To discuss this paper, please submit up to 500 words to the editor at journals@ice.org.uk. Your contribution will be forwarded to the author(s) for a reply and, if considered appropriate by the editorial board, it will be published as a discussion in a future issue of the journal. 